It is shown by experiment that it is sufficient to arrange between the polar pieces of an electromagnet a hori. zontal photographic plate upon which is placed, in the centre of a little leaden dish, the radiating source of very small diameter. The rays emanating normally to the plate and brought back orthogronally on it are the most efficarious; the impression, large and diffuse, is thrown on one side of the field, and constitutes a sort of spectrum which is sufficiently pure. If one works in the dark, and places on the plotographic plate bands of various substances, aluminium leaf, copper and platinum foil, $\&$ c., it is seen that under the screens the impression of the deviated rays is limited by elliptic arcs, distinguished from each other. Each screen arrests different radiations, the most deviated being the most absorbable. The dimensions of the elliptic arcs are in accordance with theory. The absorption is the same in air and in an absolute vacuum. These experiments constitute a sort of magnetic spectrum analysis of the deviable radiation.

The identification of this radiation with the kathode rays requires two other verifications--the demonstration of the existence of a transport of electric charges and that of a deviation in an electrostatic field. M. and Mine. Curie have made the first verification, and I lave realised the second. M. and .Mme. Curie placed a screen, isolated from all contact with the air, in connection with an electrometer, and observed that the radium radiation chárged this screen negatively, whilst the source itselt, if it is properly isolated, is charged positively. The current for each square centime:er of radiating surface was about $4 \cdot 10^{-13}$ electromagnetic C.G.S. units.

For my part, I showed that in an electric field the radiation of radium undergoes a parabolic inflection in the contrary sense to the field, as would be the case with a flux of negatively charged particles. The comparison of the electrostatic and magnetic deviations allows of the determination, like that of Prof. J. J. Thomson for the kathode rays, of the velocity of the particles. For the particular radiations defined by $\mathrm{H} \rho=\mathrm{I}(600$, the velocity has been found equal to $1.6 \times 10^{10}$ about one-half of that of light. The ratio of the material masses carried off to the charges which they transport has been found equal to $10^{-7}$, a number identical with that corresponding to the kathode rays. From these numbers, and that which results from the experiment of $M$. and $M m e$. Curie, it follows that for each square centimetre of surface of the radiating substance studied there escapes a flux of material which would amount to a loss of about one milligramme in one thousand million years. If the material emission, which appears to be of the same order as the evaporation of certain scented substances, is the first cause of the observed phenomena, there would be no contradiction betiveen the apparent absence of any source of energy and the continuous emission of this energy.

The most deviable portions of the radium radiation pass easily through all bodies when they are very near the source, but are stopped when these bodies are some centimetres distant. I have further recognised that, after having traversed a screen, the radiation possesses the same magnetic deviability.

I can only give here the physical properties of radioactivity. One of the most important applications has been the discovery, by $M$. and Mme. Curie, of new chemical elements. Radium has a high atomic weight, and a characteristic spectrum observed by $M$. Demarçay. Polonium, according to recent researches, has a spectrum in the ultra-violet. These bodies possess, then, the characters of simple substances.

Recent studies on induced radio-activity appear to open still new horizons. It has been mentioned already that a body becomes temporarily active when it receives the radiation of an active body. $M$. and Mme. Curie NO. 1634 , vOL. 63$]$ and $M$. Giesel have recognised that the induced activity thus provoked was much greater if the body was mixed in solution with an active salt and then afterwards separ. ated by precipitation. In thus rendering barium active with actinium, M. Debierne has recognised that the active barium behaves as a different body from ordinary barium, that it could be separated chemically and concentrated. Active barium thus resembles radium. It differs from it by the absence of a peculiar emission spectrum and by the fact that its activity weakens with time. I would add that recently Sir W. Crookes, who has made numerous experiments by the photographic method, announced that he had prepared uranium that was almost inactive. According to these experiments, as well as those of M. Debierne, M. Giesel and myself, it would appear to follow that the activity of uranium is due in great part, if not altogether, to a small quantity of actinium or of another radio-active body.

These facts, although increasing the complexity of radio-activity from the chemical point of view, do not, however, remove from it its value; it can be remarked that if the existence of uranium as a simple body had been unknown up to the present, its radiant properties would have permitted of its isolation, even though they are not inseparable from its existence.

This short account shows that a new order of phenomena has arisen from the study of a new property of matter-radio-activity.

HENRI BECQLEREL.

\section{PROGRESS OF THE MAGNETIC SURVEY OF THE UNITED STATES.}

$\mathrm{THE}$ special division of the United States Coast and Geodetic Survey devoted to the magnetic survey of the United States, and countries under its jurisdiction, was created by the late superintendent, Dr. H. S. Pritchett, now president of the Massachusetts Institute of Technology, on July I, 1899 ; and Dr. L. A. Bauer was put in charge of the division. Since that date magnetic observations-namely, declination, dip and intensity of magnetic force, have been made up to December 3 I, I900, at about 500 stations distributed over the United States, Alaska and the Hawaiian Islands. At most of the stations permanent marks have been established for the use of the surveyor. Special consideration has also been given to the needs of the mariner, especially in Alaskan waters, where occur places of pronounced local attraction affecting the compasses on board ship all the way from 4 of a point to 4 points.

Special stations, known as "repeat" or "secular variation" stations, have also been established in different parts of the United States. At these, observations will be repeated at stated intervals in order to determine the amount of secular change in the magnetic elements. It is the endeavour, whenever possible, to establish such stations in the vicinities of colleges and universities, as experience has shown that on college grounds there is hope for a permanency of station for a fairly long interval.

Of special State surveys mention may be made first of the completion of the magnetic survey of Maryland, which was undertaken primarily by the Maryland Geological Survey and assistance rendered by this I3ureau; second, the completion of the magnetic survey of North Carolina, conducted under the joint auspices of this Bureau and the North Carolina (ieological Survey; third, the completion of the magnetic survey of West Virginia ; and fourth, the completion of the magnetic survey of Iowa.

Fair progress has also been made in the establishment of the magnetic base stations, where the countless variations of the earth's magnetism will be recorded photo: graphically. 'Ihus, a temporary magnetic observatory 
has been in operation at Baldwin, Kansas, since July r, I 900 , and the buildings for the primary or principal magnetic base station, situated at Cheltenham, Md., sixteen miles south-east of Washington, have been completed and the installation of the instruments is now taking place. Special declination readings from 7 a.m. to 4 p.m. have been made at Gaithersburg, Md., since March 22, 1900, and at Sitka, Alaska, since October I, I900, The sites for the magnetic base stations at Sitka, Alaska, and near Honolulu, Hawaiian Islands, have been determined and preparations made for the erection of the buildings. It will be the endeavour to have these magnetic observatories completed in time for co-operation with the proposed Antarctic expeditions.

Furthermore, special simultaneous observations have also been made on special days at various times, the purpose of these special observations being to determine over how large an area the variations, as recorded at the base stations, may be regarded as applying.

Again, various special investigations both of an experimental and a theoretical character have been undertaken, and considerable attention has been paid to the thorough training of observers and to the proper correlation of the various magnetic instruments. During the autumn of I 899 a set of coast survey magnetic instruments was compared with the standard instruments at the following foreign observatories: Kew, England; Potsdam, Germany; Pavlovsk, Russia ; and Parc St. Maur, France.

The following publications have been issued, namely: Appendix 9, giving a general report of the magnetic survey of North Carolina; and Appendix IO, on the magnetic work of the U.S. Coast and Geodetic Survey, both appendices appearing in the Report of the Survey for 1898-99. Good progress has also been made with the new edition of the Coast Survey's magnetic declination tables and isogonic charts for the United States and Alaska for 1900 .

\section{MAX JOSEF VON PETTENKOFER.}

$\mathrm{T} \mathrm{T}$ is with great regret that we record the death, in very sad circumstances, of the veteran German hygienist, Prof. Max von Pettenkofer. $\mathrm{He}$ was born in I8I8, and was, therefore, in his eighty-third year at the time of his death.

Pettenkofer's name was known throughout the civilised world as that of the great professor of hygiene at Munich, and he made the Munich school famous. Among medical and hygienic circles in Europe he was personally well known and respected for his fearless defence of what he believed to be true and for the breadth of his views. Sometimes during a discussion on some subject on which he felt strongly, the burly form of the great German hygienist would arise, and with a few vigorous sentences he would scatter the arguments of his opponents like chaff before the wind. A notable instance of this occurred at the meeting of the International Congress of Hygiene and Demography at Vienna in 1887 during the discussion on quarantine; the supporters of that antiquated method of prevention had most of them aired their views, when Pettenkofer got up and brusquely told them that it was a question of cleanliness, that England had spent many millions in improving the sanitary condition of her towns and had now no fear of cholera, and that what other countries should do was to follow England's example, and then they would have no need for the vexatious and, for the most part, useless restrictions of quarantine.

Pettenkofer published a great many valuable papers on public health subjects; the list of their titles fills nearly a page and a half of the great "Index Catalogue of the Library of the Surgeon-General's Office, United States Army"; and even that is not complete, as it does not NO. 1634 , vOL. 63$]$ include his remarkable paper on "Die Immunität von Lyon gegen Cholera." But he was too busy with teaching the many pupils who flocked to him from all parts of the world, and with investigating, to write large treatises, two on cholera being the longest productions of his pen ; this, indeed, was his favourite subject, and his books and papers on it number about a score, the best known of them probably being the one entitled "Boden und Grundwasser in ihren Beziehungen zu Cholera und Typhus,". in which he propounds his well-known theory that the spread of cholera and enteric fever depends upon the movements of the subsoil water, their prevalence increasing after a fall in the level of that water. This view he stoutly maintained, undaunted even by the fact that the City of Lyons (the invariable immunity of which from epidemics of cholera, in spite of several introductions of the disease, he considered quite explicable on his theory) was very subject to enteric fever, from which it ought, on the same theory, to be immune.

Whether, however, we regard his ground-water theory as correct or not, we cannot but admire the practical results of the measures taken under his advice to purify the subsoil of Munich, which, from being a hotbed of enteric fever, has become remarkably free from that disease.

He also wrote on sewerage arrangements, on the hygiene of ships, and on "the relations of the air to clothing, dwelling and soil," the last being a course of popular lectures ; and he was co-editor of the Zeitschrift fitr Biologie (München) from 1865 to 1882 .

Pettenkofer was much interested in chemical work connected with hygiene, and devised the method (ever since known by his name) of determining the percentage of carbonic acid in air, which has been adopted by all observers until quite recently.

Personally he was gentle and amiable, as a little incident will suffice to show. In 1894 the present writer, not finding him at the International Congress of Hygiene at Budapest, went to see him at his home at Seeshaupt, on the Starnberger See, near Munich; he was crossing on one of the steamers, and, when about half way towards the farther end of the lake, was surprised to meet Pettenkofer on board. The latter had gone some distance round the lake by rail and got on the steamer at one of the stopping places, so as to come part of the way to meet his guest for the day and escort him to his house.

Not having received the usual New Year's greetings from him on a card bearing a photograph of one of the fountains of the "Pettenkofer water supply" at Munich, with a small profile medallion of the professor above it, the writer feared that he was not well, but was little prepared for the terrible news which so soon followed.

It was no doubt his retirement, even at that lovely spot, and his forced inactivity, that preyed upon poor Pettenkofer's mind, and not even the patent of hereditary nobility granted him by the Emperor seems to have solaced him, for we have just received the melancholy and pathetic news that this grand old man, tortured by an incurable disease and wearied by his inability to work any more for the benefit of his fellow-men, has put an end to his sufferings by a pistol-shot.

W. H. C.

\section{THE ROYAL INDIAN ENGINEERING COLLEGE, COOPERS HILL.}

AST week we printed a report, taken from the daily papers, of the deputation to the Secretary of State for India asking for an inquiry into the working of the Royal Indian Engineering College. Lord Kelvin, who headed the deputation, expressed disappointment at the nature of Lord George Hamilton's reply, and if, in criticising that reply, we should fall into error in consequence of the inconsistencies in the reports of the 